\title{
ISOLATION AND FUSION OF PROTOPLASTS FROM THE PHYTOPATHOGENIC FUNGUS SCLEROTIUM ROLFSII (SACC.)
}

\author{
Sikandar Hayat ${ }^{1} *$, Christos Christias $^{2}$ \\ ${ }^{1}$ Post-Doctoral Fellow Alberta Research Council, Vegreville, Alberta, Canada; ${ }^{2}$ Professor of Microbiology University of Patras,
} Greece.

\begin{abstract}
Sclerotium rolfsii (Sacc.) is a serious plant pathogenic fungus and lacks perfect (basidial) stage in production. Protoplast fusion technology was employed to reconstruct fusants from this fungus. Two strains designated as A and R were used. Maximum protoplast yields of $3.8 \times 10^{5} / \mathrm{g}$ mycelia and $2.8 \times 10^{5} / \mathrm{g}$ mycelia were formed in strains A and R respectively. Osmotic stabilizer sucrose $1 \mathrm{M}$ gave maximum yield. Lysing enzyme at the rate of $15 \mathrm{mg} / \mathrm{ml}$ was found best for yield. Fusion of protoplasts from strains A and R was carried out in fusion media containing PEG $400030 \%(\mathrm{w} / \mathrm{v})$ with $0.2 \mathrm{mM} \mathrm{CaCl}_{2}$. Four fusants $\mathrm{F} 1, \mathrm{~F} 2$, F3 and F4 were recovered. Morphological, physiological and pathogenic characters of fusants were compared with parent strains on carrots, beans and tomato.
\end{abstract}

Key words: Protoplast, fusion, Sclerotium rolfsii, Pathogenicity and osmotic stabilizer.

\section{INTRODUCTION}

Protoplast fusion represents an approach to gene transfer in microbial organisms including bacteria and fungi. Protoplast Fusion Technology (PFT) has been used to bypass many natural barriers to cross-breeding in fungi, as reported in numerous species of Deuteromycetes, where no sexual cycle exists $(14,17,22,29)$. Protoplast fusion allows investigators to bypass mating type and incompatibility group barriers $(7,9)$ to study mitochondrial genetics, $(8,21)$. Hyun-Choi et al (16) performed inter-generic protoplast fusion in Saccharomycopsis fibuligera and Saccharomyces cerevisiae. Salamiah et al (27) applied protoplast fusion system in non-pathogenic Alternaria alternata and a tomato pathotype Alternaria alternata using electrofusion and PEG and studied pathogenicity in hybrid strains. Couteaudier et al (6) fused protoplasts of two different strains of entomopathogenic fungus Beauveria bassiana to get fusants for more effective control against Ostrinia nubilalis.

Sclerotium rolfsii is a serious plant pathogen fungus. Its perfect stage is very rare in nature. In addition the complete absence of asexual spores in this fungus results inability of use of traditional hybridization techniques for the development of new strains. In view of serious economical losses caused by this fungus, protoplast fusion technology being inexpensive and simple technology was used in this study. This is the first report of construction of new strains from the inter-strains protoplast fusion from Sclerotium rolfsii.

\footnotetext{
*Corresponding Author. Mailing address: Post-Doctoral Fellow Alberta Research Council, Vegreville, Alberta, Canada.; Tel.: 780-632-8225.; E-mail: hayat@arc.ab.ca
} 


\section{MATERIALS AND METHODS}

\section{Materials}

Two strains of Sclerotium rolfsii designated as A and $\mathrm{R}$ were used through out the study. Strain A was isolated from Myoporum sp. (5). Strain R a cotton isolate was obtained from The National Institute of Biology, Athens, Greece. Osmotic stabilizers including Sucrose, Sodium Chloride $(\mathrm{NaCl})$, Potassium Chloride $(\mathrm{KCl})$, Ammonium Chloride $\left(\mathrm{NH}_{4} \mathrm{Cl}\right)$ were purchased from Merck Germany. Magnesium sulphate $\left(\mathrm{MgSO}_{4}\right)$ was purchased from Reidel-de Hach AG Germany. Lysing enzyme (Trichoderma harzianum), Cellulase (Aspergillus niger), Driselease (Basidiomycetes), Chitinase (Serretia marcescens) and Beta-Glucuronidase (Helix pomatia) were purchased from Sigma Chemicals Co. (St Louis, USA).

\section{Media and growth conditions}

Potato Dextrose Agar (PDA) media was prepared boiling $200 \mathrm{~g}$ of potato and adding $20 \mathrm{~g}$ of glucose and $15 \mathrm{~g}$ of agar in total volume of $1000 \mathrm{ml}$. Media was autoclaved at $121^{\circ} \mathrm{C}$ for 15 minutes and used for cultivation of fungal culture.

\section{Preparation of semi-permeable cellophane membranes}

Semi-permeable cellophane membranes $(9 \mathrm{~cm}$ diameter) were used to harvest clean and pure mycelia of the fungus, free of any traces of agar from the Petri-dishes. Sterile cellophane membranes were transferred on Petri-dishes and were inoculated with $5 \mathrm{~mm}$ mycelial disc of strain $\mathrm{A}$ and $\mathrm{R}$ and were incubated at room temperature for 4-5 days.

\section{Pre-treatment of mycelia and preparation of digestion mixtures}

One gram of three days old mycelia from the both strains was incubated in $20 \mathrm{ml}$ of $\mathrm{NaCl} 0.9 \mathrm{M}$ pH 5.8 for 20 minutes for pre-treatment. Digestion mixtures were prepared using different osmotic stabilizers including sucrose $1 \mathrm{M}, \mathrm{NaCl} 1 \mathrm{M}$, $\mathrm{KCl} 0.9 \mathrm{M}, \mathrm{NH}_{4} \mathrm{Cl} 1 \mathrm{M}$ and $\mathrm{MgSO}_{4}(0.4 \mathrm{M}, 0.6 \mathrm{M}, 0.8 \mathrm{M}$ and $1 \mathrm{M})$ at $\mathrm{pH}$ 5.8-6.0 containing different lytic enzymes. Lysing enzyme was used at the rate of $5 \mathrm{mg}, 10 \mathrm{mg}$ and $15 \mathrm{mg} / \mathrm{ml}$,
Cellulase $15 \mathrm{mg} / \mathrm{ml}$, Driselease $15 \mathrm{mg} / \mathrm{ml}$, Chitinase $1 \mathrm{mg} / \mathrm{ml}$ and Beta-glucuronidase $0.06 \mathrm{mg} / \mathrm{ml}$ in the digestion mixture. The digestion mixtures were autoclaved at $121 \mathrm{C}$ for 15 minutes prior to the addition of lysing enzymes.

\section{Protoplast formation}

One gram of fresh 3 days old pre-treated mycelia was mixed in digestion mixture in a total volume of $10 \mathrm{ml}$ using each osmotic stabilizer and lysing enzyme in a $50 \mathrm{ml}$ Erlenmeyer flask in triplicates and was incubated in a rotary shaker incubator at $75 \mathrm{rpm}$ at 30C for 24 hours. Samples were taken at 6, 12 and 24 hours to observe under the microscope for cell wall digestion and protoplast formation.

\section{Protoplast purification}

The reaction mixture containing protoplasts and cell wall debris was harvested after 24 hours and filtered through sterilised cheese cloth to remove undigested materials under aseptic conditions. The filtrates were centrifuged at $3000 \mathrm{rpm}$ for 15 minutes at $15 \mathrm{C}$. The protoplasts were collected as pellet. The protoplasts were washed in the same osmotic stabilizer to remove lysing enzyme traces. The purified protoplasts were resuspended in the osmotic buffer. The size and number of protoplasts was determined per ml per gram of fresh weight of mycelia using haemocytometer. The average size of protoplasts was expressed in micrometer $(\mu \mathrm{m})$.

\section{Regeneration of protoplasts}

Regeneration of protoplasts was carried out using $1 \mathrm{ml}$ of reaction mixture containing $\left(1 \times 10^{3}\right)$ protoplasts in both solid PDA and liquid PD media. The different phases of regeneration of protoplasts into germ-tubes and hyphal cells were recorded under the microscope.

\section{Protoplast fusion}

Protoplast fusion was performed according to a modified method of $(1,2)$. A sample of $0.5 \mathrm{ml}$ of the purified protoplast suspension $\left(1 \times 10^{5}\right)$ of strains $\mathrm{A}$ and $\mathrm{R}$ was mixed and centrifuged at $800 \mathrm{rpm}$ for 10 minutes at $15 \mathrm{C}$. The pellet was 
re-suspended in a fusion medium in a total volume of $1 \mathrm{ml}$. The fusion medium was prepared by adding poly-ethyl-glycol (PEG) $4000,30 \%(w / v)$ and $0.2 \mathrm{mM} \mathrm{CaCl}_{2}$ in $1 \mathrm{M}$ sucrose. The fusion mixture was incubated for 30 minutes at 30C. Samples were taken from fusion mixture and were spread on Petridishes containing PDA regeneration media. The fusants were picked on the basis of different pattern of mycelial growth comparing with parent strains A and R.

\section{Stability and growth rate of fusants}

The stability of fusants was studied upto three generations in PDA media. Growth rate of fusants was compared with parent strains and was expressed in $\mathrm{mm}$.

\section{Study of properties of fusants in green house}

A growth chamber experiment was carried out on three crops namely tomato, carrots and beans to study morphological, physiological and pathogenic parameters of fusants comparing with the parent strains A and R.

A 550grams of garden soil was inoculated with homogenized mycelia (slurry) in plastic bags with air pores. The soil bags were kept at $25 \mathrm{C}$ for 10 days in order for fungal cultures to be established and proliferate in the soil. Three-four days old seedlings of each crop were transplanted into soil bags and kept in green house.

Morphological parameters like plant height $(\mathrm{cm})$, number of leaves, leaf mid rib, fresh and dry weight of plants were studied and the data was analysed. Physiological parameters including chlorophyll fluorescence was measured by plant efficiency analyzer (PEA) in beans only. Plants infected with fusants, strains $\mathrm{A}$ and $\mathrm{R}$ and control were kept in dark conditions for 1 hour before measuring fluorescence. The data in the form of initial fluorescence $\left(\mathrm{F}_{0}\right)$, Maximum fluorescence $\left(F_{M}\right), F_{V}$ variable difference between $F_{0}$ and $F_{M}$ and ratio of $\mathrm{Fv} / \mathrm{F}_{\mathrm{M}}$ were recorded on PEA monitor. The ratio $\mathrm{Fv} / \mathrm{F}_{\mathrm{M}}$ value was used for chlorophyll fluorescence determination. This ratio has been shown to be proportional to the quantum yield of the photochemistry (3).

\section{Estimation of chlorophyll $a, b$ and carotenoids}

The total chlorophyll amount and individual amounts of chlorophyll a $(\mathrm{Ca})$, chlorophyll b $(\mathrm{Cb})$ and carotenoids in the leaf samples were measured according to the method of Lichtenthaler and Wellburn (20). Leaf samples were homogenized in $5 \mathrm{ml}$ of $80 \%$ acetone and then centrifuged at $5000 \mathrm{rpm}$ for 5 minutes. Supernatant was collected and volume was made upto $5 \mathrm{ml}$ with $80 \%$ acetone and stored in darkness. The measurements were taken using spectrophotometer (Ultraspec 4050), LKB Biochem, England at three wavelengths, 663, 646 and 470nm. The following formula was used to calculate chlorophyll $\mathrm{a}, \mathrm{b}$ and carotenoids. The individual amount of chlorophyll a, b and carotenoids was expressed in micrograms $(\mu \mathrm{g})$ per $\mathrm{ml}$ of leaf extract.

Chlorophyll a, 12.21 $\mathrm{A}_{663}-2.81 \mathrm{~A}_{646}$

Chlorophyll b 20.13A $\mathrm{A}_{646}-\mathbf{5 . 0 3}_{663}$

Carotenoids $x+c=1000 A_{470}-3.27 \mathrm{Ca}-104 \mathrm{Cb} / 229$

\section{Statistical Analysis}

All the data on growth and physiological parameters were analyzed using one-way ANOVA and LSD test at $\mathrm{P}=0.05$ level by SPSS 9.0 and means were compared for significance.

\section{RESULTS AND DISCUSSION}

\section{Optimization of protoplast yields from Sclerotium rolfsii}

\section{Effect of osmotic stabilizers on protoplast yields}

All osmotic stabilizers were used at $1 \mathrm{M}$ concentration except $\mathrm{KCl}(0.9 \mathrm{M})$. Strain A produced maximum protoplasts of $3.8 \times 10^{5} /$ gram fresh weight of mycelia in $1 \mathrm{M}$ sucrose and strain $\mathrm{R}$ gave maximum protoplast yields of $2.8 \times 10^{5}$ in the same stabilizer (1M sucrose) after 24 hours incubation. Among osmotic stabilizers, $1 \mathrm{M}$ sucrose was found to be optimum for protoplast yields in both strains followed by $1 \mathrm{M} \mathrm{NaCl}$ (Figure 1)

\section{Effect of different lytic enzymes on protoplast yield}

Five different commercial lytic enzymes including lysing enzyme at the rate of $15 \mathrm{mg} / \mathrm{ml}$, cellulase (8.55units), driselease $15 \mathrm{mg} / \mathrm{ml}$, chitinase (0.072units) and beta-glucuronidase (600units) were test in a reaction mixture. All lytic enzymes 
Hayat, S. et al.

except lysing enzyme did not produce protoplasts in both strains A and R. Lysing enzyme at the concentration rate of
$15 \mathrm{mg} / \mathrm{ml}$ was found optimum for the isolation of protoplasts in strains A and R (Figure 2).

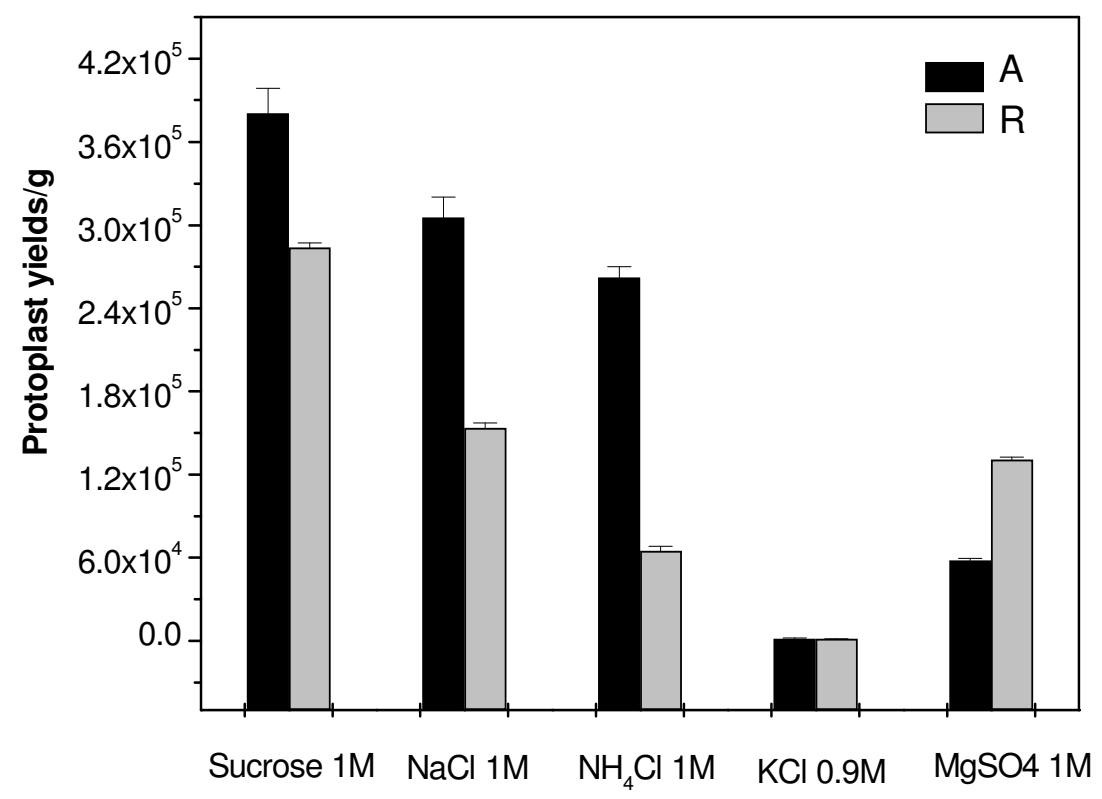

Figure 1. Effect of different osmotic stabilizers on protoplast yields of strains A and R of Sclerotium rolfsii, lysing enzyme $15 \mathrm{mg} / \mathrm{ml}$ at $\mathrm{pH} 5.81 \mathrm{~g}$ mycelia and incubation period 24 hours

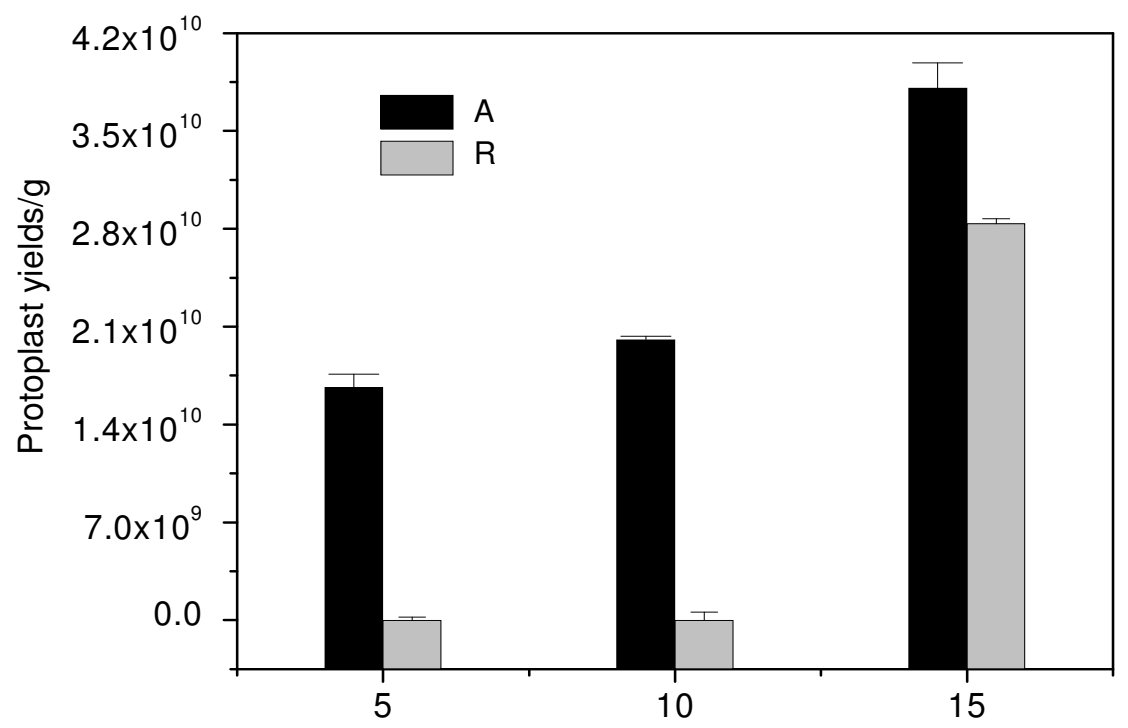

Figure 2. Effect of different concentrations of lysing enzyme on protoplast yields of strains A and R of Sclerotium rolfsii, lysing enzyme $15 \mathrm{mg} / \mathrm{ml}$ at $\mathrm{pH} 5.8 \mathrm{1g}$ mycelia and incubation period 24 hours 


\section{Size of protoplast}

The size of 150 protoplasts of both strains A and R was measured randomly and the average size were found $15 \mu \mathrm{m}$.

\section{Regeneration of protoplasts}

The regeneration of protoplasts of both strains $A$ and $R$ was started within 15 minutes after incubation in solid and liquid media. The protoplasts of both strains formed bud like structures, which developed into germ tubes. These germ tubes later formed hyphal cells in 2-3 days. The protoplasts of both strains formed sclerotia like the parent strains (Figure 3)

\section{Fusion of protoplasts of strains $A$ and $\mathbf{R}$}

Protoplast fusion experiment was conducted to recover possible fusants. The results indicated that the fusion frequency was very low as only four (4) fusants were recovered. It was found under the microscope during the fusion, that both fusing protoplasts after breaking down their cell membranes merged their cytoplasmic contents (Figure 4). The four fusants recovered were designated as F1, F2, F3 and F4. All four fusants were found different from the parent strains and with each other in morphology and sclerotia formation. F1 showed thin and aerial growth of mycelia with whitish color. Few sclerotia aggregates were also formed. F2 showed different morphology from parent strains and other fusants. The mycelia were thick and it did not produce sclerotia which was found a rare character in this fungus. F3 exhibited different pattern of sclerotial formation, it formed aggregates of smaller size sclerotia along the periphery of the Petri-dishes. F4 derived characteristics from both strains $\mathrm{A}$ and $\mathrm{R}$. It formed sclerotia small in size like strain A along the edge of Petri-dish unlike strain A (Figure 5).

Stability experiments showed that out of 4 fusants, 3 were found stable after three generations, while one fusant F3 lost its acquired characters like mycelial morphology and sclerotial formation.
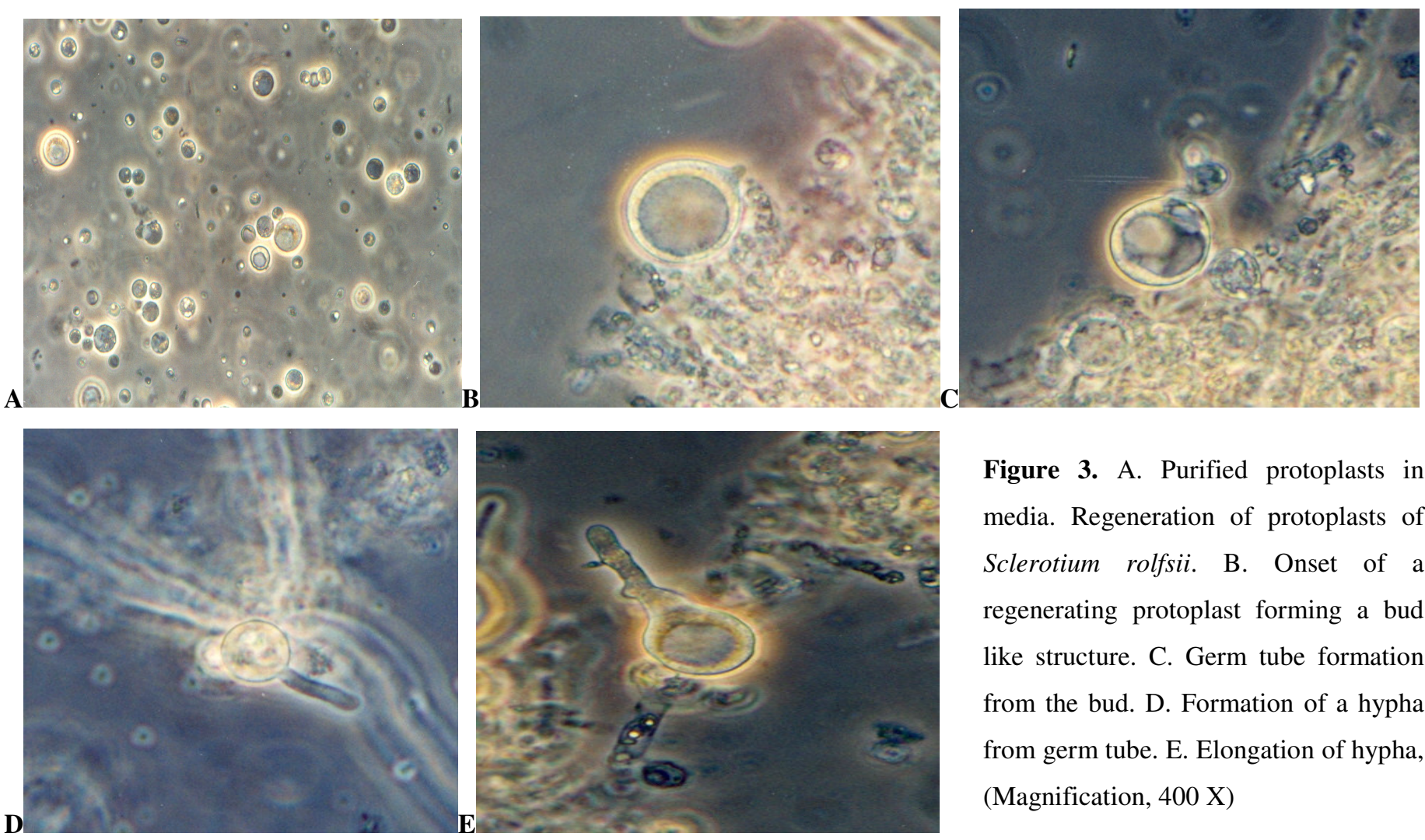

Figure 3. A. Purified protoplasts in media. Regeneration of protoplasts of Sclerotium rolfsii. B. Onset of a regenerating protoplast forming a bud like structure. C. Germ tube formation from the bud. D. Formation of a hypha from germ tube. E. Elongation of hypha, (Magnification, 400 X) 

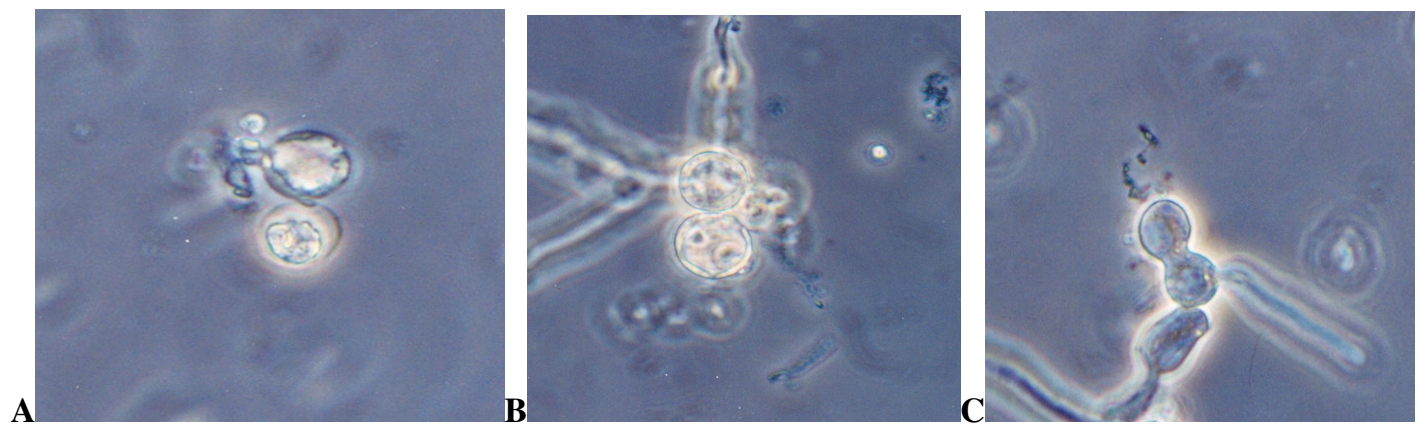

Figure 4. Fusion of protoplast of strains A and R of Sclerotium rolfsii, A. Close contact of two fusing protoplasts, B. rupture of membranes of fusing protoplasts, C. Complete rupture of membranes of fusing protoplasts and merging of cytoplasmic contents (Magnification, $400 \mathrm{X}$ )

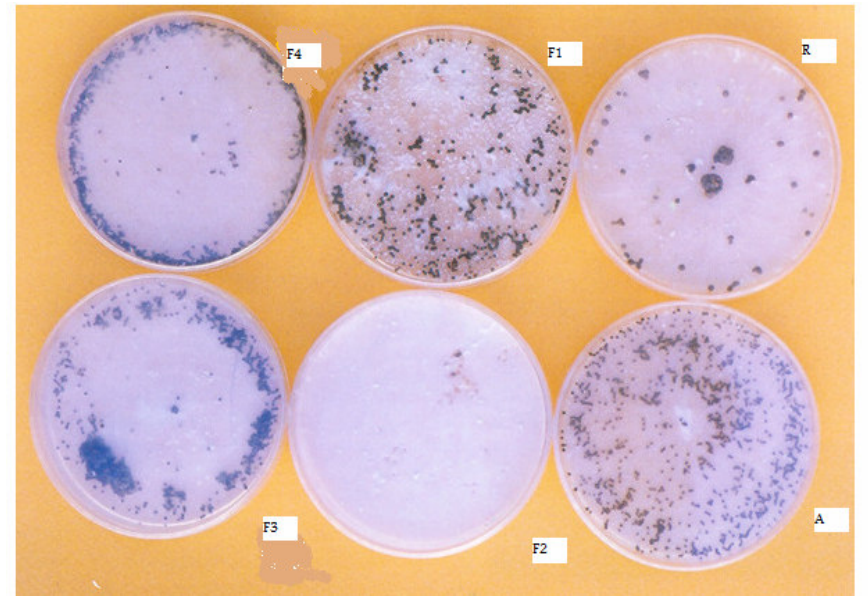

Figure 5. Parent strains A and R of Sclerotium rolfsii and fusants F1, F2, F3 and F4. Strain A has thin mycelia, produces large number of small-sized sclerotia. The sclerotia are present all over the Petri dish. Strain R shows thick mycelia with large sized sclerotia few in numbers. F1 shows aerial growth pattern of mycelia and whitish in color. The sclerotia are produced in irregular manner in the Petri dish. F2 has thick mycelia with complete absence of sclerotia. F3 exhibits aggregation of small sized sclerotia, black in color. The aggregations of sclerotia are present at the periphery of the Petri dish. F4 shows small size sclerotia in chains present at the periphery of the Petri dish.

\section{Assessment of pathogenicity of fusants and parent strains}

The pathogenic characteristics like plant wilting and mortality percentage were investigated in fusants as compared to the parent strains $\mathrm{A}$ and $\mathrm{R}$ on host crops like tomato, carrots and beans. The growth parameters like plant height, number of leaves, leaf mid rib length, fresh and dry weight of plants and physiological parameters like chlorophyll a, b, carotenoids and chlorophyll fluorescence was also determined.

\section{Mortality \%}

The mortality was determined as percentage of dead plants. The mortality rate was 0 in tomato plants infected with fusants as well as parent strains A and R. Leaf discoloration was found in plants infected with F1 and A strain. Mortality rate of $40 \%$ was noted in two months old carrot plants infected with $\mathrm{F} 1$ and $20 \%$ in F4.No mortality was reported in plants infected with F2 and F3 and parent strains A and R. The data 
showed that F1 was found to be the most virulent as compared to other fusants and parent strains.

Highest mortality of $78 \%$ was noted in two months old bean plants infected with strain A as compared to F1 the most virulent fusant as well as strain $\mathrm{R}$. The results indicated that among host crops, beans were highly susceptible to pathogenic strains A and R.

\section{Growth parameters}

The data on morphological parameters including plant height, fresh and dry weight of plants in tomato plants infected with fusants and parent strains $\mathrm{A}$ and $\mathrm{R}$ showed significant results comparing fusants to the parent strains $\mathrm{R}$ and control in plant height, fresh and dry weight of plants. Two months old carrot plants infected with fusants and parent strains, plants infected with F1 showed significant results in all morphology parameters comparing within fusants and to parent strains and control. In case of bean, plants infected with a parent strain A had significant results when compared to fusants, parent strain $\mathrm{R}$ and control.

\section{Physiological parameters}

Chlorophyll fluorescence was measured as an indicator of plant efficiency infected with pathogenic strains only in beans. The $\mathrm{Fv} / \mathrm{F}_{\mathrm{M}}$ ratio was measured and a maximum ratio of 0.8426 was noted in plants infected with F3 and results were found non-significant when compared within fusants and with parent strains (Figure 6).

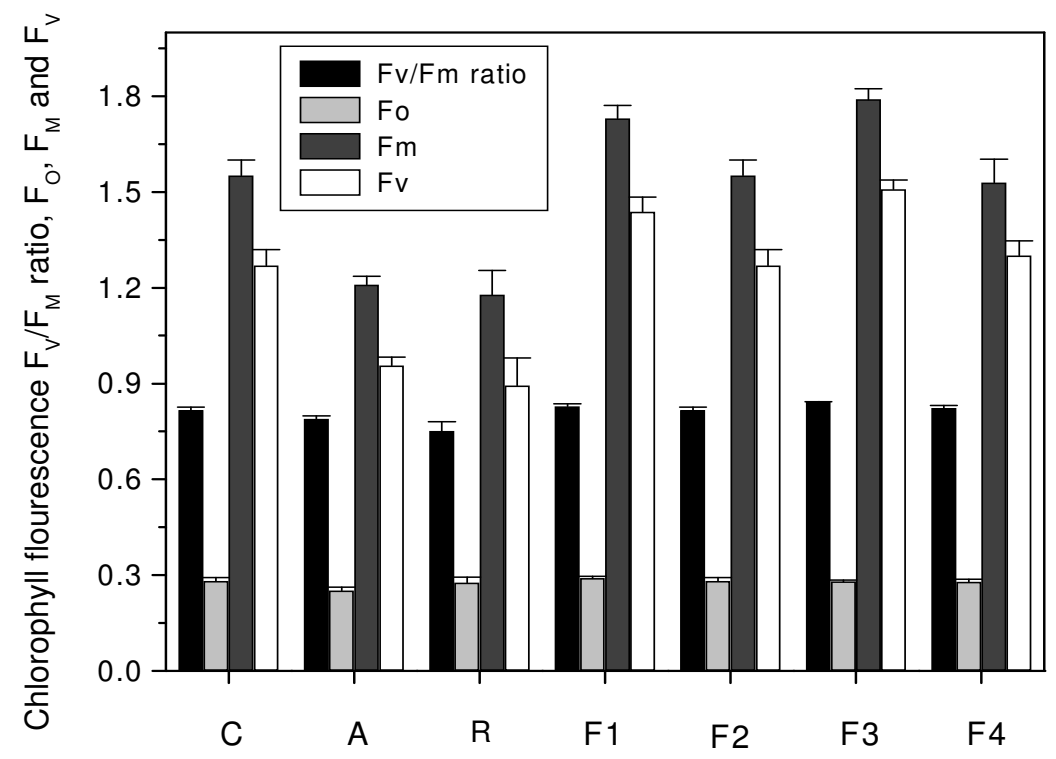

Figure 6. Chlorophyll fluorescence in beans leaf (two months old plants) infected with parent strains A and R and fusants F1, F2, F3 and F4 and control. The vertical bars represent standard errors

\section{Estimation of chlorophyll $a, b$ and carotenoids}

Maximum chlorophyll (Ca) of $16.02 \mu \mathrm{g} / \mathrm{cm}^{2}$ was determined in leaves of plants infected with F1 and minimum amount of $4.36 \mu \mathrm{g} / \mathrm{cm}^{2}$ was found in the leaves infected with the parent strain R. Highest amount of chlorophyll $(\mathrm{Cb})$ of 3.55 $\mu \mathrm{g} / \mathrm{cm}^{2}$ was recorded in the leaves of plants infected (Figures 7 and 8) with F1and maximum carotenoids content of 1.01 $\mu \mathrm{g} / \mathrm{cm}^{2}$ were noted in the leaves of plants infected with F4 and were found significantly different from the $0.293 \mu \mathrm{g} / \mathrm{cm}^{2}$ in the plants leaves infected with parent strain $\mathrm{R}$. 
Hayat, S. et al.

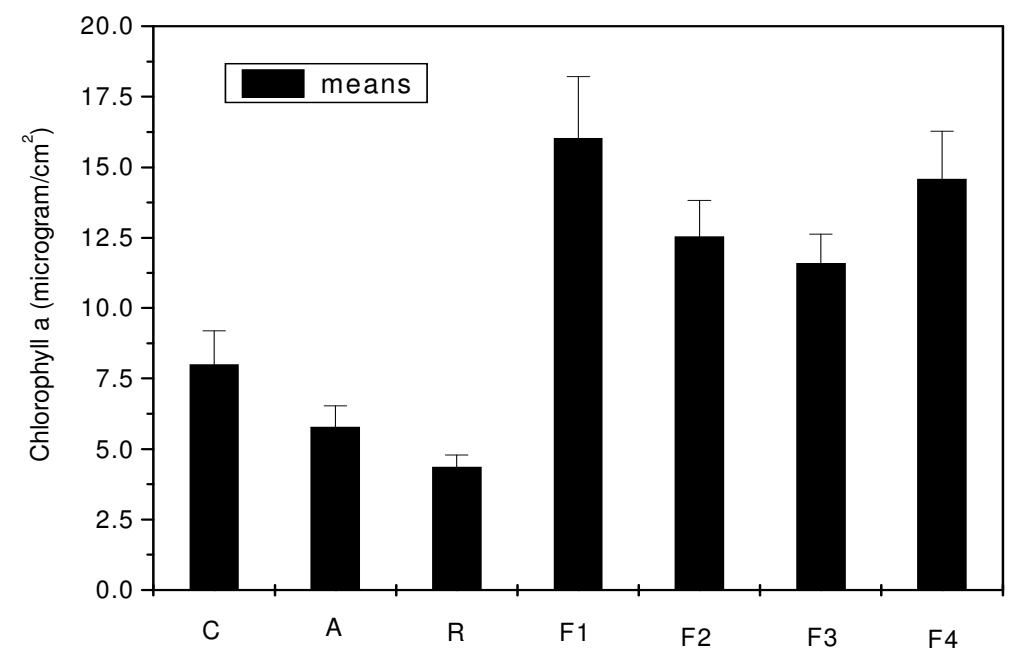

Figure 7. Chlorophyll a in beans leaf (two months old plants) infected with parent strains A and R and fusants F1, F2, F3 and F4 and control. The vertical bars represent standard errors

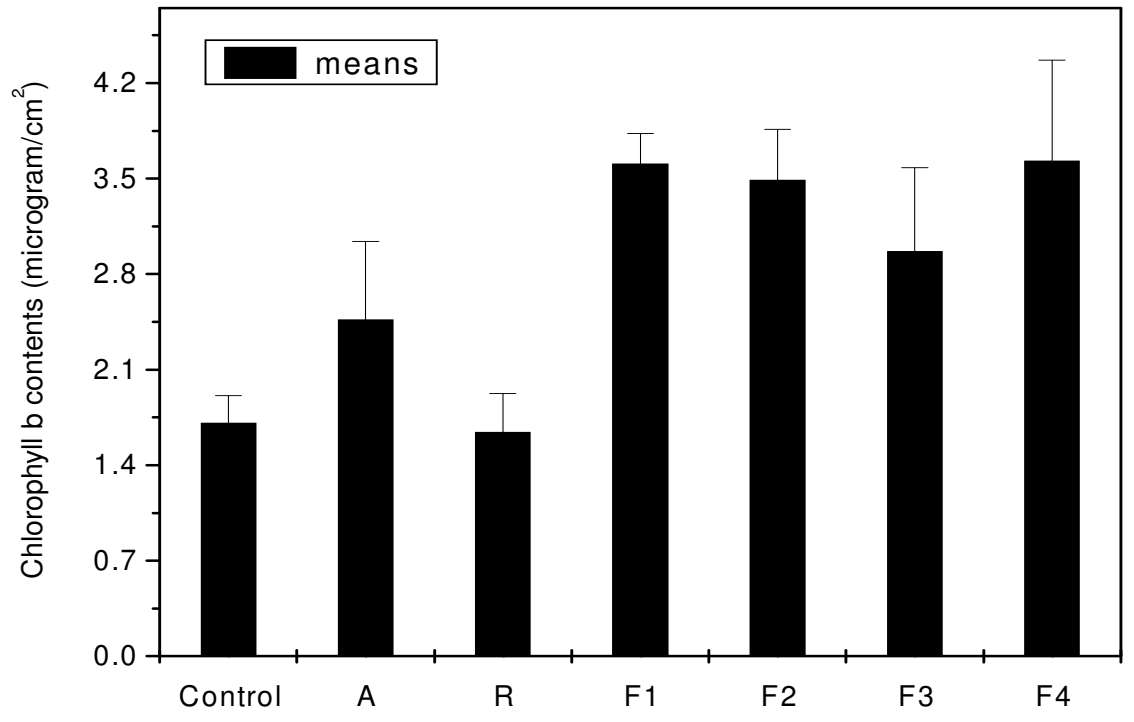

Figure 8. Chlorophyll $b$ in beans leaf (two months old plants) infected with parent strains A and R and fusants F1, F2, F3 and F4 and control. The vertical bars represent standard errors

In this research work, the aim was to isolate protoplasts from the two morphologically different strains $\mathrm{A}$ and $\mathrm{R}$ of the phytopathogenic fungus Sclerotium rolfsii and then to construct fusants from these protoplasts. There is one report of isolation of protoplasts from Sclerotium rolfsii by Deshpande et al. (10),
Kelkar et al. (18) and another report by Farina et al. (12) on the formation and regeneration of protoplasts in Sclerotium rolfsii ATCC 201126. They reported optimization of different culture conditions for protoplast formation. Protoplasts were isolated and purified from both strains using lysing enzyme $(15 \mathrm{mg} / \mathrm{ml})$ 
in $1 \mathrm{M}$ sucrose as osmotic stabilizer. The lysing enzyme from Trichoderma harzianum was found to be the most effective enzyme in our study with Sclerotium rolfsii. Our results are supported by Farina et al (12) and Quigley et al. (26), when they used commercial novozym-234 for the isolation of protoplasts in Sclerotium rolfsii and Neurospora respectively. To-date, there has been no rational explanation for the superiority of one stabilizer over other. Our studies showed sucrose and $\mathrm{NaCl}$ were the most effective stabilizers for protoplasts yields. Van Diepeningen et al. (11) used 1M sucrose for the isolation of protoplasts from Aspergillus nidulans, whereas Farina et al (12) reported $0.6 \mathrm{M} \mathrm{MgSO}_{4}$ osmotic stabilizer for protoplast formation. The regeneration of protoplasts in sucrose solution showed that most of protoplasts were found viable and our findings of protoplasts viability are according to Cheng and Belanger (4). They reported $75 \%$ viability of Pseudozyma flocculosa protoplasts regeneration in $0.8 \mathrm{M}$ sucrose medium. The size of protoplasts in both strains A and $\mathrm{R}$ was measured $15 \mu \mathrm{m}$, which was found larger as compared to the size of protoplasts of Sclerotium rolfsii reported by Deshpande et al (10). The reason for the different protoplasts size can be due to the use of different isolates of Sclerotium rolfsii and use of sucrose as stabilizing agent in media in our studies. Protoplasts of both strains regenerated to their normal vegetative cells both in liquid and solid media. They formed bud like structures and increased its mass led to the formation of germ tube which eventually gave rise hyphal structures. The regeneration frequency of protoplasts was not enough high in solid media. Peberdy (24) reported 0.1-50\% regeneration frequency in fungal protoplasts. Protoplast fusion technology provides an alternative approach to obtain genetic recombination in imperfect fungi (Hashiba and Yamada, (15); Peberdy, (23) and Typas, (30). In Sclerotium rolfsii, there is no report of intra-specific protoplast fusion so far. Therefore, protoplast fusion technology was employed to construct fusants from two distinct strains of this fungus. The results showed fusion frequency was not enough high as compared to fusion frequencies in other fungi species. Only four fusants were recovered and designated as F1, F2, F3 and F4. Kirimura et al.
(19) reported fusion frequency of $3.6 \%$ in Aspergillus niger. As there is no report of protoplast fusion in Sclerotium rolfsii it is difficult to compare the fusion frequency of Sclerotium rolfsii with other fungi genus. Ferenczy et al. (13) described PEG as the most important factor affecting protoplast fusion frequency. Punja and Sun (25) investigated genetic diversity among species of Sclerotium rolfsii and reported difficulty in genetic exchange and proposed construction of genetic markers for further exploration. Four fusants F1, F2, F3 and F4 were recovered on the basis of morphology and sclerotial formation from the strains A and R. Three fusants F1, F2 and F4 were found stable and F4 was found unstable after three generations and showed stability percentage of $75 \%$, while Salamiah et al (28) reported $5.4 \%$ in Alternaria alternata. There are only two reports on the pathogenicity of fusants derived by protoplast fusion, one by Yang et al. (31) in Rhizoctonia solani and other by Salamiah et al (28) in Alternaria alternata. In our study on pathogenicity of fusants on three host crops, tomato, carrots and beans, growth parameters and physiological parameters like chlorophyll fluorescence and chlorophyll a, b and carotenoids contents were studied as indicators. The data showed F1 was found hyper-virulent among fusants and as compare to strains A and R. Among host crops, the beans showed totally opposite behaviour to fusants and showed growth promotion unlike in other two host crops. This growth promotion behaviour of beans was also supported by the data on chlorophyll florescence and chlorophyll contents. This selective expression of plant growth promoting in one crop and pathogenic behaviour in another crop might be due to species specificity or synthesis of growth promoting substances triggered by certain genes.

In conclusion, during our study protoplast fusants were constructed successfully using protoplast fusion technology. The pathogenicity of fusants derived from protoplast fusion of strains $\mathrm{A}$ and $\mathrm{R}$ of Sclerotium rolfsii provided value able information about different host-pathogen relationships. Further research is required to carry out complete genetic analysis of fusants and parent strains to correlate physiological and growth parameters with virulence in this fungus. 
Hayat, S. et al.

\section{ACKNOWLEDGEMENTS}

This study was funded by a grant from (IKY) State

Scholarship Foundation, Athens, Republic of Greece.

\section{REFERENCES}

1. Anne, J. (1982). Comparison of penicillins produced by inter-species hybrids from Pencillium chrysogenum. European Journal of Microbial Biotechnology, 15: 41-46.

2. Anne, J.; Peberdy, J.F. (1975). Conditions for induced fusion of fungal protoplasts in polyethylene glycol solutions. Arch. Microbiol., 105: 201205.

3. Butler, W.L.; Kitajima, M. (1975). A tripartiate model for chloroplast fluorescence. In: Proceeding of the $3^{\text {rd }}$ International Congress on Photosynthesis. Edited by Avron, M. 13-24, Elsevier, Amsterdam.

4. Cheng, Y.; Belanger, R.R. (2000). Protoplast preparation and regeneration from the spores of the bio-control fungus Pseudozyma flocculosa. FEMS Microbiol. Lett., 190, 287-291.

5. Christias, C. (1975). Specific inhibition of sclerotium formation by 2mercaptoethanol and related sulfhydryl compounds in Sclerotium rolfsii. Can. J. Microbiol., 21: 1541-1547.

6. Couteaudier, Y.; Viaud, M.; Riba, G. (1996). Genetic nature, stability and improved virulence of hybrids from protoplast fusion in Beauveria. Microb. Ecol., 32: 1-10.

7. Croft, J.H. (1985). Protoplast fusion and incompatibility in Aspergillus. In: Fungal protoplasts: Applications in Biochemistry and Genetics J.F. Peberdy and L. Ferenczy, Marcel Dekker, New York, PP.225-240.

8. Croft, J.H.; Dales, R.B.G.; Turner, C.; Earl, A. (1980). The transfer of mitochondria between species of Aspergillus. In Advances in Protoplasts Research Ferenczy, L and G.L. Farkas, Akademiai Kiado, Budapest, Pergamon Press Oxford, pp. 85-92.

9. Dales, R.B.G.; Croft, J.H. (1977). Protoplast fusion and isolation of heterokaryons and diploids from vegetatively incompatible strains of Aspergillus nidulans. FEMS Microbiol. Lett., 1: 201-204.

10. Deshpande, M.V.; Balkrishnan, H.; Ranjekar, P.K.; Shanker, V. (1987). Isolation and immobilization of Sclerotium rolfsii protoplasts. Biotechnol. Lett., Vol.9, (1), 49-52.

11. Dipeningen, A.D. van; Debets, A.J.M.; Hoekstra, R.F. (1998). Intra and inter-specific virus transfer in Aspergilli via protoplast fusion. Fungal Genetic and Biology, 25, 171-180.

12. Farina, J.I..; Molina, O.E.; Figueroa, L.I.C. (2003). Formation and regeneration of protoplasts in Sclerotium rolfsii ATCC 201126. J. Appl. Microbiol., Vol.96, (2) 254-262.

13. Ferenczy, L.; Kevei, F.; Szegedi, M.; Franko, A.; Rojik, I. (1976) Factors affecting high frequency fungal protoplast fusion. Experientia, 32: 1156-1158.
14. Fournier, P.; Provost, A.; Bourguignon, C.; Heslot, H. (1977). Recombination after protoplast fusion in the yeast Candida tropicalis. Arch. Microbiol., 115: 143-149.

15. Hashiba, T.; Yamada, M. (1984). Intra-specific protoplast fusion between auxotrophic mutants of Rhizoctonia solani. Phytopathology, vol. 74, No.4 398-401.

16. Hyun-Choi, S.; Sung, C.; Oh, M.; Kim, C. (1997). Inter-generic protoplast fusion in Saccharomyces fibuligera and Saccharomyces cerevisiae. J. Ferment. Bioeng., 84: 158-161.

17. Kakar, S.N.; Partridge, R.M.; Magee, P.T. (1983). A genetic analysis of Candida albicans: Isolation of a wide variety of auxotrophs and demonstration of linkage and complementation. Genetics, 104: 241-255.

18. Kelkar, H.S.; Shankar, V.; Deshpande, M.V. (1990). Rapid isolation and regeneration of Sclerotium rolfsii and their potential application for starch hydrolysis. Enzyme Microb. Technol. 12, 510-514.

19. Kirimura, K.; Yanuchi, T.; Usami, S. (1986). Intra-specific protoplast fusion of citric acid producing strains of Aspergillus niger. Journal of Fermentation Technology, 64: 473-479.

20. Lichtenthaler, H.K.; Wallburn, A.R. (1983). Determination of total carotenoids and chlorophyll $\mathrm{a}$ and $\mathrm{b}$ of leaf extracts in different solvents. Biochem. Soc. Trans. 11, 591-592.

21. Maraz, A.; Subik, J. (1981). Transmission and recombination of mitochondrial genes in Saccharomyces cerevisiae after protoplast fusion. Mol. Gen. Genet., 181: 131-133.

22. Peberdy, J.F. (1980). Protoplast fusion: a tool for genetic manipulation and breeding of industrial microorganisms. Enzyme Microb. Technol., 2: 23-29.

23. Peberdy, J.F. (1989). Presidential address: Fungi without coatsprotoplast as tool for mycological research. Mycol. Res., 93: 1-20.

24. Peberdy, J.F. (1991). Fungal protoplasts. In : More gene Manipulation in Fungi by Bennett, J.W.; Lasure, L.L. pp. 307-318, Academic Press, California.

25. Punja, Z.A.; Sun, L. (2001). Genetic diversity among mycelial compatibility groups of Sclerotium rolfsii (telemoroph Athelia rolfsii) and Sclerotium delephini. Mycol. Res. 105: 537-546.

26. Quigley, D.R.; Taft, C.S.; Stark, T.; Selitrennikoff, C.P. (1987). Optimal conditions for release of protoplasts of Neurospora crassa using novozm 234. Exp. Mycol., 11, 236-240.

27. Salamiah, A.H.; Fukumassa-nakai, Y.; Otani, H.; Kodama, M. (2000). Genetic analysis of pathogenicity and host-specific toxin production of Alternaria alternate tomato pathotype by protoplast fusion. J. Gen. Plant Pathol., 67: 7-14.

28. Salamiah, A.H.; Fukumassa-nakai, Y.; Otani, H.; Kodama, M. (2001). Construction and genetic analysis of hybrid strains between apple and tomato pathotypes of Alternaria alternate by protoplast fusion. J. Gen. Plant Pathol., 67: 97-105.

29. Shimizu, S. (1987). Protoplast fusion of insect pathogenic fungi. In: Biotechnology in invertebrate Pathology and cell Culture by $\mathrm{K}$. Maramorosch, Academic Press, San Deigo, pp. 401-414. 
Protoplasts from S. rolfsii

30. Types, M.A. (1983). Heterokaryon incompatibility and inter-specific hybridization between Verticillium alboatrum and Verticillium dahliae following protoplast fusion and microinjection. J. Gen. Microbiol., 129: 3043-3056.
31. Yang, H.A.; Zhou, J.; Sivasithamparam, K.; O'Brien, P.A. (1994). Variations in culture morphology and pathogenicity among protoplastregenerated strains of Rhizoctonia solani. FEMS Lett., 115: 83-86. 